Revista Española de Antropología Americana ISSN: 0556-6533

https://doi.org/10.5209/REAA.63689

\title{
Al sur del lejano Oeste: marginalidad, ambivalencia y anacronismo en las clasificaciones culturales desde la perspectiva sur-barbacoa
}

\author{
Montserrat Ventura i Oller ${ }^{1}$
}

Recibido: 26 de abril de 2017 / Aceptado: 10 de diciembre de 2017

Resumen. El grupo sur-barbacoa, entre el Pacífico y los Andes ecuatoriano-colombianos, ha sido clasificado en la periferia del «Área intermedia», a veces solapando, otras reemplazando o lindando un conjunto lingüístico-cultural antes denominado chibcha. El texto analiza en primer lugar los avatares de su errática ubicación en las clasificaciones arqueológicas, lingüísticas y culturales a lo largo de la historia. En segundo lugar, recurre en clave comparativa a datos históricos y etnográficos de dos sociedades sur-barbacoa, tsachila (colorado) y chachi (cayapa), particularmente sobre sistemas de organización socio-política, chamanismo, redes de intercambio y formas de relación y de identificación entre humanos y no humanos, es decir, datos que nos informan tanto de la dinámica social como de la ontología. Finalmente, el artículo propone una superación de las fronteras culturales tradicionales para comprender las sociedades indígenas de la región.

Palabras clave: sur-barbacoas; tsachila; chachi; clasificaciones culturales; chamanismo.

\section{[en] South of the Far West: Marginality, Ambivalence and Anachronism in Cultural Classifications from the South-Barbacoan Perspective}

\begin{abstract}
The South-Barbacoan group, between the Pacific and the Ecuadorian and Colombian Andes, has been placed on the periphery of the "Intermediate Area», alternately overlapping, replacing and bordering a linguistic and cultural grouping formerly known as Chibcha. Firstly, this text analyses the vicissitudes of the group's erratic positioning in archaeological, linguistic and cultural classifications throughout history. Secondly, it examines and compares historical and ethnographic data on the South-Barbacoan Tsachila (Colorado) and Chachi (Cayapa) societies, focusing in particular on systems of socio-political organisation, shamanism, exchange networks and forms of relationship and identification between humans and non-humans: in other words, data that inform us about both the social dynamics and the ontology. Finally, the article suggests reaching beyond the traditional cultural boundaries in order to understand the indigenous societies of the region.
\end{abstract}

Keywords: South-Barbacoan; Tsachila; Chachi; cultural classifications; shamanism.

Sumario. 1. Sobre el conocimiento de una región etnográfica ambigua. 2. Las descripciones arqueológicas y la historia. 3. Las clasificaciones lingüísticas. 4. Las clasificaciones etnográficas. 5. El chamanismo del área sur-barbacoa: organización social, ontologías y redes. 6. A modo de conclusión: repensando las áreas. 7. Referencias.

Cómo citar: Ventura i Oller, Montserrat. 2018. «Al sur del lejano Oeste: marginalidad, ambivalencia y anacronismo en las clasificaciones culturales desde la perspectiva sur-barbacoa». Revista Española de Antropología Americana 48: 43-63.

\footnotetext{
${ }^{1}$ Departamento de Antropología Social y Cultural, Universitat Autònoma de Barcelona. montserrat.ventura@uab.cat
} 


\section{Sobre el conocimiento de una región etnográfica ambigua}

En 1913 el Dr. Vignaud, presidente de la Société des Américanistes de París, intentaba definir en su discurso inaugural qué era el americanismo y, en pro de la lucha contra el racismo y la búsqueda de la igualdad del ser humano, se preocupaba por establecer un método riguroso. En su respuesta, Paul Rivet insistía en la sistematización empírica y la comparación prudente:

«Le problème de l'origine des populations américaines est une de ces questions. Avant de l'aborder, il est nécessaire de bien connaître ces populations, d'établir sur des bases solides leurs principaux groupements, de déterminer leurs migrations internes $[\ldots]$ Il est essentiel de n'avancer également qu'avec une extrême prudence. Le travail est surtout un travail de comparaison; preuves linguistiques, ethnographiques, archéologiques, anthropologiques, etc...» (Vignaud 1919: 19).

Un siglo más tarde, sabemos que dichos objetivos no han sido siempre neutrales. La etnología amerindia refleja una doble herencia histórica: el interés por el desarrollo de las altas civilizaciones y la fascinación suscitada por las sociedades salvajes (Taylor 1984), que han imprimido un sesgo en las tipologías y los paradigmas teóricos que las han elaborado, dejando un vacío en la comprensión de las sociedades que no encajan en su matriz. En el presente texto observaremos las dificultades que entraña el establecimiento de áreas culturales a partir del seguimiento de un caso específico, el área sur-barbacoa.

El área sur-barbacoa, entre el Pacífico y los Andes ecuatoriano-colombianos, se ha ubicado en la periferia de lo que podríamos calificar de área cultural fallida, que desde la arqueología y más recientemente la lingüística se ha posicionado en el seno o la periferia de la denominada «Área intermedia» (Constenla 1991; Lippi 2004)2, a veces solapando, otras reemplazando o lindando un conjunto antes denominado chibcha. Valga la evidencia del término para intuir la ambigüedad y dependencia que se le ha atribuido respecto a las áreas con las que intermedia. Un conjunto de sociedades que puede ser revisitado ahora gracias al progreso teórico y empírico en el campo de las fronteras culturales, de la lingüística y de la historia de la región, por un lado, y de las relaciones sociales y las ontologías, por otro. La revisión de trabajos arqueológicos, históricos, lingüísticos y antropológicos nos permitirá constatar la multiplicidad de criterios en su delimitación, con resultados no siempre consistentes. Finalmente, el diálogo de dichos resultados con el análisis de los datos etnográficos, particularmente del campo del chamanismo -institución paradigmática de las relaciones sociales y cosmológicas-, dará pie a proponer la superación de las áreas culturales tradicionales en pro de una mayor atención a las relaciones entre grupos, sin detrimento de las identificaciones particulares de sus protagonistas. Las socie-

\footnotetext{
2 La primera versión de este texto fue discutida en el simposio «Between the Andes, Amazonia and Mesoamerica: Cultures and ontologies of the Intermediate Zone» (organizado por E. Halbmayer, U. Marburg y M. Martínez Mauri), en el marco del 6th German research meeting on South America, Mesoamerica and the Caribbean (Bonn, 23-26 de mayo de 2013). Una parte del texto fue también discutido en el coloquio «Siguiendo el sol, surcando el río: las relaciones entre la selva y la costa en la región andina» (organizado por A. Surrallés y A. Díaz; Lima, 9-10 de abril de 2015). Agradezco a los organizadores de ambos encuentros su invitación e impulso a un debate fundamental. Agradezco también el apoyo del proyecto HUMANT (HAR2013-40445-P) del grupo de investigación AHCISP de la UAB.
} 
dades tsachila y chachi ${ }^{3}$, representantes contemporáneas del grupo sur-barbacoa en Ecuador, nos guiarán en este recorrido.

\section{Las descripciones arqueológicas y la historia}

Si nos centramos en el Ecuador, la arqueología del área septentrional andina y costeña ha sido particularmente fecunda (Figura 1). D. Lathrap y J. Marcos entre otros han excavado el sitio Real Alto (Península Santa Elena) desde los años setenta (Marcos 2012), documentando la Cultura Valdivia (3900-1650 a.C.) hasta el período de Desarrollo Regional (800 d.C.) y destacando su progresivo y espectacular desarrollo social y económico, con agricultura de maíz. Más al norte, el complejo ManteñoHuancavilca y los cerros de Hojas y Jaboncillo en Ciudad Alfaro, han reportado sistemas socio-políticos complejos y agricultura con irrigación durante el Período de Integración (siglos IX-XVI), eje del denominado Estado Manteño. El desarrollo de esta cultura de cerros se vio favorecido por su posición central en la red de intercambio y comercio a corta, media y larga distancia en la región, en parte por vía de la concha Spondylus, medio de intercambio simbólico y económico, hasta Mesoamérica por la costa y la Amazonía por el este (Marcos 1981, 2012).

Asimismo, el proyecto Manabí Central, llevado a cabo desde 2003 por el equipo de la Universidad Complutense de Madrid y la Misión Arqueológica Francesa en el Ecuador (Bouchard 2010; Guinea 2010), ha excavado en Japotó. Único sitio con tolas de la costa Manabita, tanto de uso doméstico como ceremonial (Guinea 2010), fue sede de la élite de un cacicazgo durante el Período de Integración. Sus habitantes desarrollaron una agricultura específica de tierras áridas, se adaptaron a los peligros del mar y practicaron el comercio marítimo a larga distancia (Bouchard 2010: 499500). Esta red de intercambio ha sido central para entender culturas descritas más al norte.

En Esmeraldas, desde los trabajos de la Misión Arqueológica Española en el Ecuador en los sitios de Atacames y La Propicia entre 1970 y 1975 (Alcina 1979; Guinea 1981), hasta finales del siglo XX, tuvieron lugar una decena de proyectos arqueológicos (Bouchard 1998: 29). Éstos han puesto de relieve un sistema sociocultural y político que controló la costa entre 500 a.C. y 300 d.C., gracias a la navegación marítima en canoas, con sede en La Tolita, en la desembocadura del río Santiago, que se habría difundido a Tumaco, al sur de la actual Colombia.

A pesar de la diversidad de criterios clasificatorios de las culturas de la región -según si se consideran desarrollos autóctonos o difusión (Bouchard 1998: 30-31)-, los arqueólogos coinciden en que todas las culturas conforman una unidad mayor, pendiente de caracterización, que denominan Área Septentrional Andina, o Subárea Andina Septentrional, comprendida entre el Sur de Colombia, todo el Ecuador y el extremo norte del Perú (Guinea 1995: 3-4); a su vez, la mayoría de especialistas del área concuerda en destacar la importancia del intercambio a lo largo de la costa hasta

\footnotetext{
3 Los datos sobre la población tsachila son fruto de un trabajo etnográfico de varios años en distintos períodos (entre 1991 y 2016), principalmente en la comuna de Cóngoma y en menor medida en Naranjos y Chigüilpe, especialmente sobre las nociones de persona, chamanismo, cosmología e identidad. Agradezco a todas las personas de dichas comunidades que han contribuido a este trabajo, basado en las técnicas clásicas de observación participante y entrevistas en profundidad. Los datos sobre la población chachi surgen fundamentalmente de una revisión bibliográfica.
} 


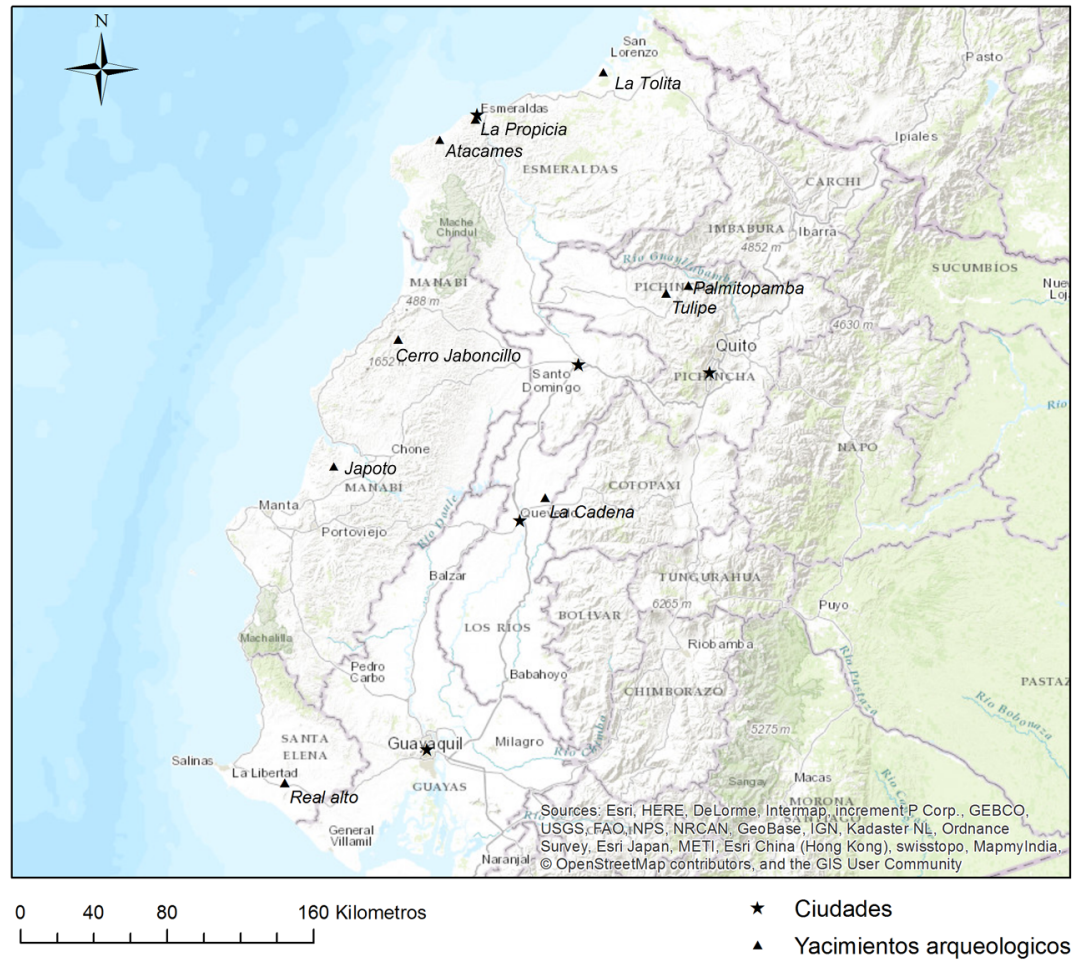

Figura 1. Yacimientos arqueológicos mencionados en el texto. (Elaboración de Igor Bogdanović).

Colombia y Perú (Guinea 1998: 83-84) y hacia el interior, hasta la Sierra e incluso a tierras más lejanas (Bouchard 1998: 31). A lo largo del texto regresaremos a la red de intercambios como eje central de la clasificación cultural regional.

Todavía en La Tolita, Ugalde (2006) analiza la iconografía de las figurillas (metálicas o cerámicas), no ya para establecer tipologías culturales con base en elementos tecnológicos; como representación simbólica de las sociedades que la elaboraron, la iconografía de la Tolita reproduce algunas de las invariantes presentes en buena parte del área Andina, como las cabezas-trofeo o las máscaras transformacionales. Más adelante la cosmología y el chamanismo nos servirán también para proponer la superación de las áreas culturales.

Hacia el interior, el proyecto arqueológico «La Cadena-Quevedo-La Maná», al norte de la cuenca del Guayas, registra la presencia de montículos artificiales (tolas) ${ }^{4}$ fechados entre 1600/1400-950 a.C. Las excavaciones iniciadas en 1992 en la región muestran que su función no era exclusivamente funeraria y que estas estructuras son paradigmáticas de la complejidad habitacional, socio-política y ceremonial de los

\footnotetext{
${ }^{4}$ El diccionario de la Real Academia Española atribuye la etimología de una de las acepciones de tola, de uso en Ecuador, al quichua, con el significado de «tumba en forma de montículo, perteneciente a los antiguos aborígenes». Sin embargo en Ecuador designa genéricamente pirámides y montículos artificiales, cuya forma y dimensiones varían según la región y los períodos de construcción. La arqueología ecuatoriana, que discute sobre su función, repartición, cronología, y adscripción cultural, las ha asociado tradicionalmente con sociedades jerarquizadas (Guillaume-Gentil 1999: 25-27).
} 
pueblos que las construyeron. En toda su extensión temporal y espacial se encuentran cerámicas de estilos plurales asociados con el litoral y Santa Elena o de estilos más locales, así como objetos exóticos que evidencian intercambio intenso de la región costera con la sierra, dada su ubicación intermedia (Guillaume-Gentil 2010).

En el interior de la región Noroccidental del Ecuador se iniciaron las investigaciones arqueológicas en los años ochenta. En Tulipe (Nanegal, Nanegalito, Gualea y Pacto, en el subtrópico quiteño), se han encontrado numerosas tolas y «piscinas» ${ }^{5}$. Sus resultados sugieren que los yumbos, según H. Jara provenientes de la costa, desarrollaron todo su proceso cultural en el área durante el Período de Integración como una comunidad costeña: sus características medioambientales se asocian más a la costa que a la sierra. Por otro lado, la tradición de las tolas, las técnicas constructivas de las casas (tipo rancho), el uso y valoración del Spondylus, el sistema alimenticio, entre otros, son manifestaciones y representaciones culturales costeñas. Sin embargo, aunque sus vínculos con la sierra eran exclusivamente de corte comercial, evidencias encontradas en Tulipe guardarían una mayor conexión con los pueblos serranos (Jara 2007: 35).

En Palmitopamba (también parroquia de Nanegal) las campañas desde 2002 han mostrado la construcción sistemática de tolas, entierros yumbos, elementos de construcción y otros del período Inca que demostrarían la cohabitación de ambas culturas durante un intervalo, además de los lazos de intercambio con la sierra (Lippi 2004; Lippi y Gudiño 2013). A partir de un repaso exhaustivo de las investigaciones arqueológicas, geológicas, etnohistóricas y lingüísticas hasta el momento, Lippi (2004) elabora un mapa de las migraciones de las poblaciones de yumbos hasta el período colonial (Figura 2). Aceptando una remota afiliación chibcha de las lenguas barbacoas, tanto de sus actuales hablantes (chachi, tsachila y awa) como de los desaparecidos en tiempos coloniales (caranqui, panzaleo, niguas, yumbos septentrionales al norte, sigchos y yumbos meridionales al sur) en Ecuador, Lippi les atribuye una procedencia centroamericana (de Costa Rica y Panamá). De esta migración distingue las poblaciones proto barbacoas septentrionales (PBS) guambiano y awá (hablantes de coaiquer o kwaiker) mayoritariamente en el sur de Colombia, y la meridionales (PBM) tsachila (hablantes de tsafiki) y chachi (de cha'palaachi) ${ }^{6}$ en Ecuador. La fisión barbacoa se habría producido en el centro o sur de Colombia entre 1900 y 50 a.C., las poblaciones PBM habrían migrado al sur por la sierra y después hasta el flanco occidental andino, mientras que las PBS se habrían movido hacia la costa y posteriormente hacia el sur por las tierras bajas (Lippi 2004: 263). Ello se explica por un largo período de despoblamiento (entre 300 a.C. y 800 d.C.), debido a una extensa actividad volcánica en el occidente andino ${ }^{7}$. Según Constenla (1991) y Stark (1983), cha'palaachi y tsafiki se habrían separado entre 740 y 1000 d.C ${ }^{8}$. A partir del 800 d.C. encontraríamos un aumento rápido de la población con presen-

\footnotetext{
5 «Piscinas» es el término local para referirse a estructuras hundidas, que conservaban el agua en invierno y parte del verano cuando fueron descritas en 1978-1980, con formas geométricas, rampas y acueductos, con funciones ceremoniales, según Jara (2007: 83 y ss.).

6 El autoglotónimo es cha'palaa pero aquí reproduzco la terminología usada por los autores.

7 Existe un consenso general entre los arqueólogos y geólogos en la región, de que la baja en el número de sitios en ciertas áreas se debió al incremento en la actividad volcánica, que también afectó el flanco occidental de los Andes (Lippi 2004: 263).

8 Actualmente, junto a chachi (9000 personas, cayapa) y tsachila (2640, colorado), hay en territorio ecuatoriano el grupo awá (3.500, cuaiquer) y epera (300, embera), procedentes de Colombia (Consejo de Desarrollo de las Nacionalidades y Pueblos del Ecuador - CODENPE, Ecuador: http://www.codenpe.gob.ec).
} 


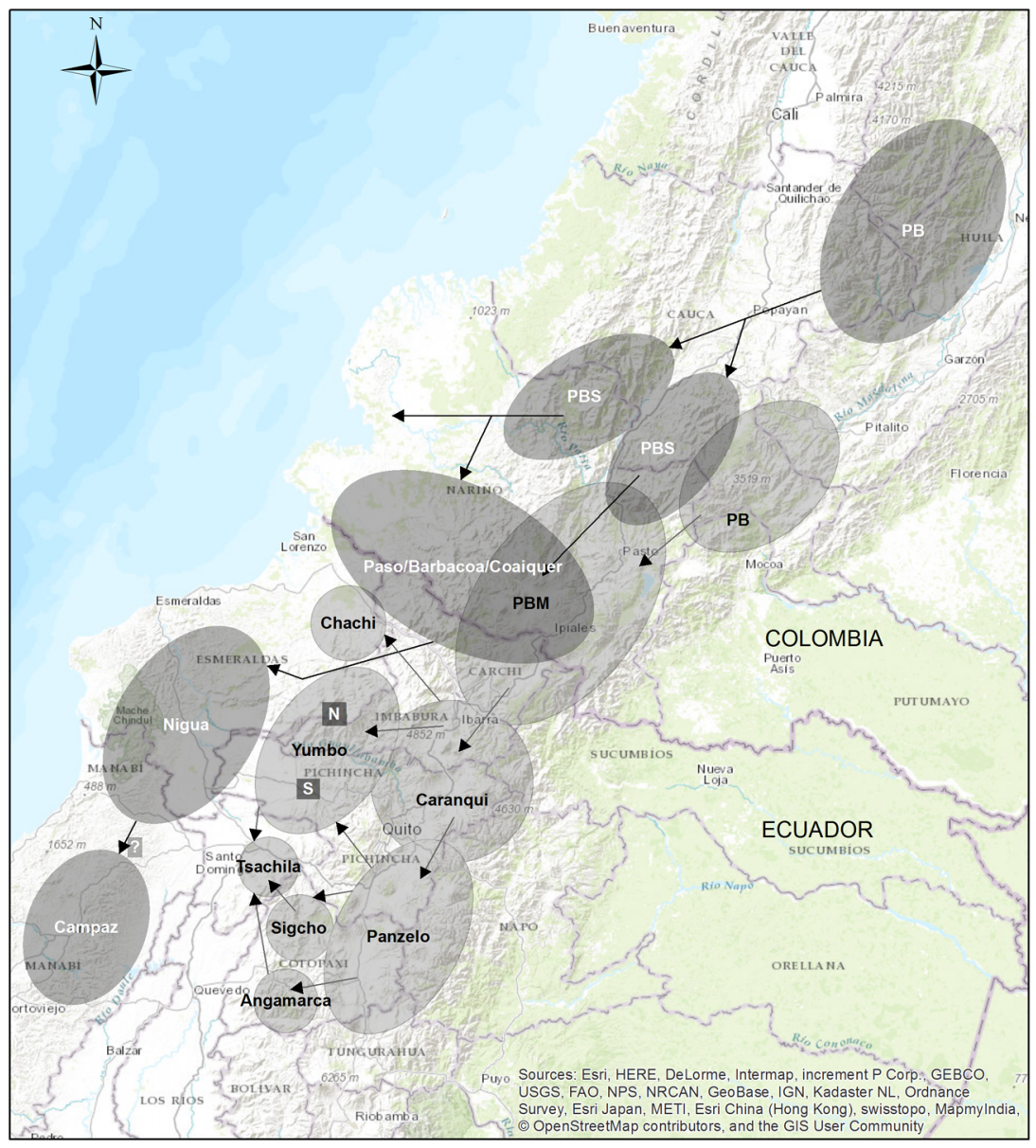

Figura 2. Migraciones barbacoas (según Lippi 2004).

(Elaboración de Igor Bogdanović)

cia de cacicazgos y agricultura de maíz, que procedería de la sierra. Unos habrían migrado hacia el sur de Quito (panzaleos) y después el occidente andino (yumbos del sur) y se habrían mezclado con pobladores anteriores retornados, produciéndose «mestizaje cultural y biológico» (Lippi 2004: 264). Este grupo diezmado por la presión colonial vivió un proceso de etnogénesis junto a otros grupos emparentados con los yumbos del sur (angamarcas y sigchos), dando lugar (según Salomon 1997), a los antecesores de los actuales tsachila. Las poblaciones PBM asentadas en las regiones de Imbabura (yumbos del norte) se habrían expandido hacia la costa por las cuencas de los ríos Cayapas y Santiago en Esmeraldas constituyendo la actual población chachi. A diferencia de los anteriores, su hábitat se caracteriza por la construcción de tolas piramidales, montículos habitacionales y ceremoniales, una alfarería próxima a la serrana y unas rutas de intercambio con la sierra extensas y bien documentadas, con el algodón y la obsidiana como productos destacados. Según Lippi, los yumbos originados de los PBM fueron poblaciones de selva orientadas hacia la vida en la sierra, de donde se originaron (Lippi 2004: 266). En cambio los PBS iniciaron su migración hacia regiones costeras con anterioridad, se instalaron en regiones menos 
afectadas por la actividad volcánica, se mezclaron con población local ya asentada en el área y se adaptaron a la horticultura tropical. Entre ellos se conocen los niguas que, según distintas versiones, podrían tratarse de los «indios bravos» citados en la literatura etnográfica de los chachi (Lippi 2004: 270) y que también están presentes en la mitología tsachila (Ventura 2012).

Estos resultados se iluminan, en la costa, por la labor etnohistórica de Palop y Cerdá (1995): estos autores estudian los asentamientos del área que denominan Barbacoa-Cayapa, ocupada, según fuentes de finales del siglo XVI, por pueblos cayapa, yamba, lacha, malaba, coaiquer, nurpe, barbacoa y sindagua, hablantes de lenguas denominadas «chibchas» y barbacoas (Palop y Cerdá 1995: 15) cuya filiación expondremos más adelante. Destacan que sus patrones de asentamiento eran tradicionalmente dispersos y sus sociedades presentaban una economía y organización social propias de culturas fluviales, de carácter «tribal», con un cacique principal, una cultura material «menos desarrollada» y eran en general pueblos «hostiles». El área Cayapa-Barbacoa lindaba al norte con el río Mira, los Andes al Este y por el Sur las fuentes de los ríos Daule y Babahoyo, y tenía como centro los ríos Santiago y Cayapas -hábitat principal del actual grupo étnico chachi-, que desembocan en el Pacífico, cerca del yacimiento de La Tolita. Más al sur, niguas, campaces, caraques, paches y huancavilcas tendrían un patrón de asentamiento más urbano, una economía adaptada a clima árido y habrían sido «más pacíficos» (Palop y Cerda 1995: 1516). Los autores sugieren un eventual origen andino de éstos y recogen propuestas de otros autores (Moreno 1976) que, en cambio, ponen en entredicho el eventual origen andino entonces aceptado de los pueblos cayapas, para sugerir una filiación original de éstos con los antiguos pobladores de La Tolita; empujados por los mulatos de San Mateo y Esmeraldas, habrían huido hacia el interior desde la Costa. Palop y Cerdá (1995: 25-28) relatan revueltas producidas por Malabos (en 1619) contra las tempranas reducciones de indios, que no consiguieron debilitar el proyecto colonial de un camino que enlazara Quito con el mar por el norte, y que pasaba por «pacificar» a los «indios de guerra» y mulatos de la región, con la vanguardia de los padres mercedarios y la mediación de los cayapas, indios «de paz», a fines del siglo XVI.

Hacia el interior, debemos a la labor etnohistórica de Frank Salomon (1997) el conocimiento sobre la región de los yumbos septentrionales y meridionales, los niguas y los colorados, estos últimos así denominados en los documentos en 1592 en Angamarca en la sierra y desde 1660 en las tierras bajas (Salomon 1997: 80), donde viven en la actualidad. Todos estos grupos habrían habitado una región extensa al occidente de los Andes, compartiendo rasgos culturales, complejidad social, y eventual comunicación gráfica a través de petroglifos (Jara 2007). Gracias a los caminos (Lippi 1983, 1986; Salomon 1986), habrían participado de intensas redes de intercambio costa-sierra, en la que los niguas y cayapas habrían ejercido de intermediarios entre los fuertes «señoríos mulatos $»^{9}$ y las etnias de occidente, y los yumbos, entre éstas y las serranas; los yumbos serían pueblos relativamente autárquicos, con pautas residenciales dispersas, organizados en cacicazgos formando parte de señoríos étnicos serranos, en una estructura que a medida que avanzaba la Colonia podría haber trans-

\footnotetext{
Salomon (1997: 57-74) recupera documentos que corroboran la dramática violencia atribuida históricamente a los «señores mulatos» de Esmeraldas (uno de los cuales era del linaje de los Arrobes), a menudo aplicada por indios subyugados entre los que se encontrarían los niguas; creemos que éstos estarían en el origen de los míticos Dobes de los relatos tsachila, los «indios bravos» de tiempos coloniales que también aparecen repetidamente en los mitos chachis (Praet 2014: 40-41).
} 
formado su carácter «reciprocitario» por una sumisión a los señores étnicos serranos (Salomon 1997: 95), paralelamente a la sumisión a los poderes coloniales. En este contexto su fama de brujos, corroborada en documentos (Salomon 1983, 1997: 104$105)$, les habría otorgado poder en las relaciones interétnicas. A mediados del siglo XVIII, coincidiendo con un vacío de poder colonial en la región de los yumbos meridionales, los colorados procedentes del río Toachi y Quinindé, en su expansión a tierras yumbas y niguas, habrían absorbido a los yumbos meridionales en un proceso de etnogénesis que habría dado lugar a los tsachila modernos (Salomon 1997: 96, 107); al mismo tiempo, dejan de distinguirse niguas y yumbos septentrionales y los meridionales dejan de estar bajo control colonial; se produce entonces un proceso de retirada y retraimiento durante el siglo XIX y un presente caracterizado por sociedades relativamente igualitarias hasta los años sesenta del siglo XX (Juncosa 1988) que ha propiciado que se hayan explicado en este siglo con paradigmas selváticos.

\section{Las clasificaciones lingüísticas}

Este entramado de pueblos que se han desarrollado, migrado o extinguido en la región, según muestran la arqueología y la etnohistoria, parece haberse solapado sólo parcialmente con las clasificaciones elaboradas por la lingüística desde principios del siglo XX. Basándose en argumentos léxicos y gramaticales Beuchat y Rivet (1910) demuestran que los «colorados», «cayapas» y «cuaiqueres» constituyen un grupo lingüístico. La comparación con los grupos paniquita y coconuca (que se extienden hasta la frontera meridional de Nicaragua) les permite establecer un parentesco común que corroboraría la constitución del grupo lingüístico chibcha como entidad, y que las lenguas del sur (cuya influencia llegaría hasta la desembocadura del Guayas), del grupo barbacoa, serían habladas por poblaciones migradas desde más al norte ${ }^{10}$. Para estos autores, la coincidencia del área lingüística con la construcción de tolas sería relevante. El análisis léxico y particularmente la toponimia jugarán un rol esencial en la clasificación que durante años guio la historia ecuatoriana de manos de Jijón y Caamaño (1941), quien propone igualmente una filiación chibcha para estas lenguas.

Loukotka, seguidor del método de comparación léxica, con un listado básico de 45 palabras, habla también en 1935 del tronco chibcha entre la división norteña de las lenguas andinas, una de las 94 familias lingüísticas, y sitúa el tsafiki, la lengua de los tsachila o «colorado», entre el subgrupo barbacoa del mencionado tronco. Entretanto Swadesh (1959) había publicado otra clasificación con una orientación genética léxico-estadística, que da lugar a correlaciones más remotas, pero considerando el continuum geográfico más que las categorías estancas de lenguas (Adelaar 2004: 29). Swadesh integró las lenguas chibchas en el tronco macro-maya, pero situó las barbacoas en el macro-quechua. En 1968 Loukotka incorpora la léxico-estadística de Swadesh (Loukotka 1968: 29-40; Wilbert 1968: 14) y unifica sus troncos lingüísticos en tres grandes grupos (lenguas de las tribus paleo-indias, lenguas de las tribus de las selvas tropicales y lenguas de las tribus de los Andes, en cuya división del norte situó al tronco chibcha). El grupo barbacoa del tronco chibcha incluye el yumbo junto a

\footnotetext{
${ }^{10}$ La diversidad lingüística prehispánica de la región costeña y su eventual conexión con las lenguas barbacoas ha sido analizada recientemente a partir de datos arqueológicos y etnohistóricos por Gómez Rendón (2010).
} 
otras 17 lenguas extintas y, entre las lenguas vivas, el cuaiquer o koaiker, el «cayapa o nigua» y el «colorado o tsáchela o chono o campaz o satxila o colime» (Loukotka 1968: 233-253). Kaufman (1990: 37-38) lamenta su falta de rigor muchas veces debida a la falta de información y, entre otros problemas, la inclusión de las lenguas barbacoas en el tronco chibcha por falta de evidencias.

Para Tovar y Larrucea (1984: 171) las lenguas del «Gran grupo chibcha» pertenecen al mundo mesoamericano. Sin embargo, la complejidad del territorio, que contiene zonas de «cultura superior», favorecía la fragmentación lingüística y no permitió «una unidad política indígena» (1984: 171-172). Aceptan la probable existencia de un tronco macro-chibcha, como Swadesh, pero no la difícilmente justificable lengua «proto-chibcha»: la isoglosia sería a su parecer la razón de similitudes entre por ejemplo el colorado y el cuna o el guaimí, que atribuyen a eventuales contactos marítimos entre las costas pacíficas de América Central y todo el Noroeste de América del Sur (1984: 171-172). En su Catálogo, el matrimonio Tovar distingue el chibcha propiamente dicho (muisca y tunebo, y el grupo de lenguas de la Sierra de Santa Marta) de otras siete categorías, la primera de las cuales es el «cuaiquer, colorado y cayapa», grupo «antes designado como barbacoa» (1984: 176). Para esta reedición ya se habían publicado los primeros estudios de B. Moore $(1962,1966)$, lingüista del ILV que a lo largo de los años sesenta y setenta edita un Diccionario Colorado y una docena de estudios gramaticales y comparativos, situando el tsafiki en una rama sur-barbacoa de una aceptada familia chibcha, de forma que los autores posteriores basados en su trabajo persisten en dicha clasificación. Seguimos en la consideración de la lengua tsafiki en cualidad de heterodoxa, sureña o «a la frontera externa» del chibcha. A su vez, Greenberg (1987) considera el tsafiki como parte del grupo páez, uno de los dos grupos, junto con el «chibcha propio», constituyentes del «phyllum macro chibcha».

Esta historia presenta un punto álgido en la obra magna sobre las lenguas del pacífico de Constenla (1991). Seguidor del método léxico-estadístico, un vocabulario de 154 palabras básicas le conduce a describir su área lingüística intermedia, que substituye al área chibcha pero dejando fuera, al sur, la «subárea ecuatoriano-colombiana», de la que excluye las lenguas barbacoas. Constenla sugiere que el barbacoa se divide en dos ramas: la norteña (con el awa pit y guambiano) y la sureña (con el cha'palaachi y el tsafiki). Vale decir que en un momento llega a ubicar también esta subárea en «la periferia norte del área peruana» (Constenla 1991: 138). En definitiva, las sitúa al sur y eventualmente al norte de alguna agrupación de la que parecen no ser muy protagonistas. En su más reciente clasificación de las lenguas chibchenses (Constenla 2008), éstas se dividen en paya y «chibchense nuclear» en cuyas categorías no se encuentran las lenguas barbacoas o norte-ecuatorianas.

Kaufman (1990) parte de un listado mínimo de 500 elementos léxicos para llevar a cabo la reconstrucción de la «protolengua». Además, toma en cuenta la unidad en la organización social, medioambiental y de los sistemas cognitivos de los hablantes de la protolengua, sin olvidar los eventuales desplazamientos y la difusión. Este método le lleva a establecer un panorama para Suramérica de 118 grupos genéticos (más unas 60 lenguas aisladas), entre los que se encuentra el barbacoa, con seis lenguas, formando familia con el grupo páez, y junto con otras seis familias, un eventual clúster macro páez. Entre las seis lenguas barbacoas se encuentran el cha'palaachi y el tsafiki.

Con Kaufman las clasificaciones desde la perspectiva comparativa han retomado impulso. Un ejemplo es el trabajo de Curnow y Liddicoat (1998) sobre las lenguas 
barbacoas, en el que confirman la existencia del grupo, incluyen las lenguas ecuatorianas en él (awa pit -cuaiquer-, cha'palaachi -cayapa y tsafiqui [por tsafiki] - colorado) y excluyen el páez, habitualmente considerado parte fundamental cuando no término genérico del grupo, a la vez que deja totalmente fuera de duda su no pertenencia al tronco macro-chibcha (Curnow y Liddicoat 1998: 384). Como Constenla, Curnow y Liddicoat dividen el grupo barbacoa en norte y sur y sitúan en este último el ch'apalaachi y el tsafiki (1998: 405).

Aunque buena parte de las síntesis se siguen basando en diccionarios y gramáticas realizadas en los años sesenta, a partir de los años noventa se abre una nueva época de estudios lingüísticos de rigor. El proyecto de C. Dickinson (2000, 2002, 2011), más de 25 años de investigación colaborativa con PIKITSA, un equipo de investigadores tsachila, ha aportado significativos avances en el estudio del tsafiki ${ }^{11}$, algunos de los cuales ya incorpora la primera síntesis del siglo XXI de Adelaar, significativamente en una edición sobre Lenguas de los Andes (2004). Adelaar sitúa las lenguas barbacoas en la «esfera chibcha»; sin embargo, concluye que desde un punto de vista tipológico general pertenecen a la «esfera andina», no tanto por la indudable antigua influencia del quechua, sino por una interacción previa o conexiones genéticas; pero también las lenguas barbacoas comparten fenómenos tipológicos con las lenguas chibchas (Adelaar 2004: 145-146). Repite la distinción de sus antecesores entre norte y sur-barbacoas y como ellos constituye esta última categoría con las lenguas cha'palaachi y tsafiki.

Podemos ahora señalar que tanto si partimos de la complejidad social, a veces determinada por datos arqueológicos como la construcción de tolas o la predominancia de instituciones sociales como la jefatura o relaciones coloniales de dominación o igualitarias, como si partimos de la afinidad lingüística, a veces determinada por proximidad léxica o gramatical, otras por conexiones más remotas, y a veces incluyendo datos sociales y medioambientales, los tsachila y los chachi hoy día son mayoritariamente adscritos a un grupo periférico: del flanco sur de una improbable área cultural intermedia que algunos prefieren seguir denominando chibcha; del grupo septentrional de los yumbos recompuestos durante el siglo XVIII después del declive colonial; del grupo sur-barbacoa para los lingüistas más contemporáneos, lindando pero conectados con la quimera macro-chibcha; siempre en una región intermedia y no definida entre costa y sierra.

\section{Las clasificaciones etnográficas}

Si tomamos en consideración las características eco-geográficas particulares del Ecuador, nos queda todavía buscarles un lugar en una distinción clásica en este país entre Costa, Andes y Selva, algo incongruente si consideramos la densa selva occidental descrita en tiempos históricos y hasta la colonización dirigida de los años sesenta; una frondosidad que pone en tela de juicio una correspondencia tajante entre categorías culturales, formas de organización social, lengua y adaptación al medio.

\footnotetext{
${ }^{11}$ Junto a análisis detallados del sistema evidencial o los ideófonos, cabe destacar la elaboración de una base de datos de alrededor de 3 millones de palabras, fuente de un diccionario interactivo de tsafiki con ejemplos en audio surgidos del proyecto de documentación, y un fondo documental alojado en el archivo digital central del DoBeS endangered languages documentation programme (Max Planck Institute for Psycholinguistics de Nijmegen) y el Archivo de lenguas y culturas del Ecuador (FLACSO-Andes), http://www.flacsoandes.edu.ec/lenguas-culturas/.
} 
La ambivalencia en la atribución de sus orígenes y el hecho que tanto en la costa como en las áreas nor-chibchas se hayan desarrollado sociedades complejas -con estructura jerárquica a pesar de sus sistemas agrícolas tropicales y una cosmología animista-, mientras que su eventual procedencia serrana los adscribiría a sociedades proto-estatales -con agricultura permanente y otras características cosmológicas-, nos obligan a repensar las clasificaciones realizadas desde la antropología.

Métraux (1950: 14-15) fue muy consciente de la necesidad de entender las instituciones amerindias en conjuntos coherentes, reflejada en su mapa clasificatorio que divide América del Sur en tres grandes regiones: Andina, Tropical y sub-tropical, y Marginal. Para él la región andina se caracteriza por el alto grado de civilización alcanzado por sus habitantes, que llegaron a fundar Estados poderosos, conocieron la metalurgia y numerosas artes; mientras que los pueblos del área tropical practicaban la agricultura itinerante de roza y quema, y formaron comunidades pequeñas. En el área andina sitúa tres grandes civilizaciones: la chibcha, la quechua y la araucana.

Este autor participó marginalmente en el proyecto liderado por J. Steward de un gran manual de pueblos indígenas basado en áreas culturales de corte evolucionista y determinista medioambiental. Como es sabido, el Handbook of South American Indians divide el subcontinente en cuatro grandes áreas (Tribus marginales, Civilizaciones andinas, Tribus de selva tropical, y Circum-caribes y sub-andinas), descritas en sus respectivos volúmenes ${ }^{12}$. Steward (1949: 669-772) sintetiza las características principales en un capítulo del quinto volumen en el que admite que rasgos materiales, culturales o rituales, entre otros, están diseminados por distintas áreas e imposibilitan la clasificación, por lo que su propuesta final se rige por patrones sociopolíticos y religiosos que nos servirán de referencia en nuestro análisis. El área que denomina «Circum-Caribe y Sub-Andina» correspondería, según sus mapas, a la región problematizada aquí, y especifica que su cultura material y tecnología son más próximas a la región de selva tropical, aunque con un complejo de subsistencia más «eficiente» (Steward 1949: 673) que soporta poblaciones más densas y poblados más permanentes, con clases, cautiverio de esclavos, ley, jefes, sacerdotes, chamanes y culto en templos. Steward admite la reubicación de algunos grupos, de forma que los pueblos sub-andinos de la costa (como mantas y esmeraldeños) presentan rasgos circum-caribes y en cambio otros de la región (como cayapas y colorados) son descritos como Tribus de la Selva Tropical. El Volumen 4, de 1948, dedicado al área circum-caribe ya incluía esta anomalía: un «enclave primitivo» entre «culturas avanzadas» (Murra 1948: 276-291; Steward 1948: 39-40; 1949: 703), es decir, un subgrupo heterodoxo dentro de la ortodoxia del área cultural. Esta descripción de un área cultural a medio camino de otras dos, propia del evolucionismo, y la excepción de algunos pueblos del oeste andino que no casan con los rasgos generales de la región, nos parece el nudo gordiano, teórico y etnográfico, de la indeterminación que ha sufrido la comprensión de los pueblos barbacoas.

El método comparativo de base estadística materializado en el mega proyecto del Human Relation Area Files de la Universidad de Yale a partir de los años cuarenta, también buscó clasificar este continente pero con mucha menor resonancia. Con el World Ethnographical Sample en la cabeza, el proyecto se dedica primero a delimitar los rasgos objetivos a partir de los cuales se establece la comparación, desde

\footnotetext{
${ }^{12}$ Los avatares teórico-políticos del proyecto del Handbook of South American Indians (1946-1959) han sido detallados por distintos autores; entre los últimos, Faulhaber (2012) y Cavalcanti-Schiel (2014).
} 
afiliación lingüística a tecnología y parentesco, sin considerar en ningún momento ni el contexto ni las lógicas culturales, las formas de representación o las ontologías. Murdock (1951) define en términos positivos las áreas culturales que en Steward se describían por sus ausencias y aunque considera que hay tipos culturales generales, su obsesión objetivista le inclina a comparar grupo por grupo, con un gran número de datos procedentes de monografías mayormente anglosajonas y aislándolos del contexto. Sus áreas más restringidas, no tan sujetas a la ecología, también son problemáticas: la región que nos ocupa se encuentra dentro del área «Colombiana» en su nomenclatura político-geográfica que evacua el Ecuador al situarla al lado de la «Peruana»e incluir rasgos poco útiles en regiones tan diversas internamente. En su favor diremos que hacia los años setenta este proyecto vive un cierto giro hacia la consideración de datos históricos para incluir las migraciones y la difusión en las tipologías (González Echevarría 1990).

La definición objetivista en antropología se reveló caduca, coincidiendo por un lado con la explosión identitaria (teórica y real) y la perspectiva situacionalista y dinamista (Barth 1976) que mostraron a un vasto público la importancia de las fronteras y la fluidez de su contenido; y por otro con la consideración de la historia amerindia, del lugar ocupado por las sociedades «sin historia» en los grandes complejos y redes sociales y en la situación sociopolítica global (Wolf 1982; para esta región Salomon 1980, 1997; para otras: Renard-Casevitz et al. 1988; Hill 1996; Hill y Santos Granero 2002; Whitehead 2003). Éstos invalidan la idea de su inmutabilidad para destacar su capacidad de adaptación y de agencia. El estudio de la transformación histórica permite la comparación en un mundo de interconexiones culturales crecientes; compara examinando el desarrollo de la variación cultural de fenómenos particulares a través del tiempo y sigue permitiendo a la antropología tanto la constatación de la universalidad como de la diversidad (Fox 2002: 167-184).

Quizás uno de los pocos intentos clasificatorios de los indios de América del Sur en esta clave lo encontramos en la obra de Melatti (1970, revisada en 2007; 1997) que insistía en sus virtudes pedagógicas: la reunión en áreas permite demostrar la diversidad; para evitar los anacronismos precedentes, Melatti recurre a la tipología de Galvão (1979), que reunía sólo grupos indígenas contemporáneos, y se centra en el contacto interétnico y con la sociedad nacional. Ello le lleva a reemplazar las «áreas culturales» por «polos de articulación», que aunque no den cuenta de ciertos elementos clave que sí subrayan las viejas áreas (como las formas de organización social o económica), ofrecen explicaciones más dinámicas de las agrupaciones sociales. Este criterio sin embargo necesita manejar una información compleja no siempre disponible. Así, Melatti designa los pueblos que conformaban la vieja tipología chibcha como Litorales del Noroeste (1997: 71-80) ${ }^{13}$, entre el occidente andino y el océano Pacífico (aunque para incluir a los cuna acaba incorporando también el Atlántico o Caribe). Cuenta ahora entre sus características la presencia de negros entre la población indígena, el clima tropical y subtropical, la existencia de regiones de manglar, una economía enfocada a la exportación de oro y plata en el pasado, y de plátanos en la actualidad, dirigida por patronos mestizos o extranjeros y de relevancia muy intermitente. En este polo de articulación los pueblos indígenas hablan lenguas de dos familias lingüísticas, chibcha y chocó. De la información conocida de Murra (1948), Melatti sólo recupera la referida a relaciones interétnicas entre sus grupos, incluyendo

\footnotetext{
${ }^{13}$ El Noroeste aquí se explica por su perspectiva desde el Brasil.
} 
los negros: que las cerbatanas cuna procedían del Chocó, que los chamanes de esta región visitaban los negros, y viceversa, y a los cayapas; que éstos comerciaban en la costa colombiana y ecuatoriana, mientras que los colorados conseguían veneno para sus flechas en la región amazónica de Canelos y a Quito iban a adquirir pan; resalta asimismo la influencia negra, española y quechua en su música y detalla el rito de establecimiento de compadrazgo entre negros y cayapas (Melatti 1997: 77). Con este autor situamos relaciones pero tenemos dificultades para entender afinidades y el devenir histórico. De esta perspectiva nos queda vigente sin embargo la mirada a la historia social, a las transformaciones en las formas de organización social, económica y política y a las relaciones externas, así como las respuestas que cada grupo ha elaborado en estrecho contacto con sus vecinos próximos o lejanos. La etnografía contemporánea tsachila (Ventura 2003, 2009, 2011) confirma la extensa red de relaciones de este grupo tanto económicas como chamánicas, como veremos más adelante.

Finalmente, con el cambio de siglo se afianza una nueva perspectiva teórica surgida de la experiencia amazónica, que propone una mirada a las formas de relacionarse, de identificarse y de reproducirse que tienen los seres humanos en sociedad. No es nueva en la medida que sigue el gran proyecto lévi-straussiano de buscar la unidad del pensamiento amerindio más allá de las áreas culturales ancladas en el medio y de entender su continuum. La síntesis de Descola (2005), persiguiendo el mismo objetivo comprensivo, propone una tipología que busca incorporar todas las sociedades del globo. Las ontologías son el eje en torno al cual se pueden ahora pensar las sociedades. El medio influye pero no es la base de cada «tendencia» ${ }^{14}$ : en la selva dominan unas formas de subsistencia, la caza-recolección y horticultura, que sin embargo no desembocarán en una misma forma de relación; allí encontramos predación pero también intercambio, algo que se repite en nuestra enorme zona intermedia. La gestión de la alteridad será un elemento clave en la definición de estas formas de relación, como avanzaron Carneiro da Cunha y Viveiros de Castro (1993) y anteriormente Lévi-Strauss (1991): la apertura a la alteridad como eje parecería una vía para la deconstrucción de las áreas culturales tradicionales, en pro de una comprensión más amplia de los pueblos amerindios.

En suma, el próximo reto consiste en observar las sociedades desde ambas perspectivas, histórica y ontológica, para comprender su ser-en-relación y entender así el devenir social en la región. El chamanismo como institución social y simbólica relevante de nuestra gran zona intermedia nos dará acceso a ambas miradas. Puesto que las investigaciones más recientes en Arqueología, Lingüística y Etnografía apuntan a una unidad sur-barbacoa, desde la Antropología podemos permitirnos partir de esta agrupación para observar recurrencias; y el chamanismo nos puede ayudar, como ámbito de la cultura que parece poner a las áreas en tela de juicio. Tomemos pues las etnografías chachi y tsachila como base de una comparación prospectiva.

\section{El chamanismo del área sur-barbacoa: organización social, ontologías y redes}

Organizados sobre la base de familias extensas y un hábitat semi-disperso, ahora bajo el régimen comunal, los tsachila, como los chachi (Barrett 1994 [1925]; Praet 2014),

\footnotetext{
${ }^{14}$ Para superar la noción de «áreas culturales», Descola y Taylor (1993) hablan de «tendencias culturales» que se manifiestan en el seno de conjuntos regionales coherentes.
} 
son desde inicios del siglo XX una sociedad relativamente igualitaria, ribereña, que vive de la pesca, la recolección, la caza y la agricultura de productos tropicales. Esto no habría sido así en el pasado, pues hemos visto que la arqueología, tanto si atribuye un origen costeño (o chibcha o incluso centroamericano) a los yumbos, como si sugiere su origen norteño y una migración a través de la sierra andina (Lippi 2004), concluye que los antecesores de los actuales tsachila y chachi habrían constituido sociedades relativamente jerarquizadas, con figuras de poder político y religioso, acumulación de bienes, intercambio a larga distancia, y participación en el sistema de cacicazgos y señoríos étnicos precolombinos y coloniales (Salomon 1997). Los tsachila, ya constituidos como tales en el siglo XVIII, sin eludir el intercambio, habrían desaparecido del control serrano y devenido más autárquicos y acéfalos en su relativa libertad selvática. Los chachi habrían seguido bajo cierto control colonial y probablemente su forma de organización política actual, de mayores reminiscencias coloniales, sería una consecuencia de ello, pero su retirada selvática los habría catapultado igualmente a su condición actual. Los tsachila, como los chachi del siglo $\mathrm{XX}$, fueron el prototipo de indio aislado, igualitario, referente occidental del área cultural de las tribus de la selva tropical, otro exponente de «falso arcaísmo» cuya confusión aumenta por la ambivalencia con la que han sido tratados por los estudios clásicos.

Los tsachila del siglo XXI mantienen multiplicidad de liderazgos para ámbitos específicos, desde el gobernador (el antiguo miya), el presidente comunal, el chamán (pone), o la persona destacada en algún campo particular (Ventura 2000, 2011, 2012), pero la sola figura legal prominente, ahora elegida en asamblea, el «Gobernador tsachila», hasta unas décadas atrás era un gran chamán. Los chachi también tienen un gobernador (uñi), cargo antiguamente hereditario, así como gobernadores menores (chaitaruku), suerte de «policías» cuya función es vigilar el cumplimiento de la ley tradicional sin ejercer de jefes (Medina 1997: 53, 73; Praet 2014: 91), a los cuales Barrett (1994 [1925]: 260) atribuye una adaptación del modelo colonial; ahora, como en el caso tsachila, acompañados por las autoridades comunales regidas por la ley estatal. Estos cargos actualmente de elección comparten autoridad con los chamanes (miruku para los chachi) y, si para los tsachila parece que ambas figuras podían coincidir (Ventura 2011), entre los chachi no hay evidencias de que así fuera.

Los relatos etnográficos desde inicios del siglo XX nos muestran que se mantenían con fuerza las relaciones de intercambio, particularmente chamánico, que el olvido colonial no había conseguido diluir, quizás ya no como eje central de su vida política pero sí influyendo su acción social. Los chamanes viajan a aprender con maestros de otras tradiciones, los enfermos a curarse fuera del grupo; los objetos simbólicos (piedras, flechas, agua bendita, figurillas) circulan por los mercados clandestinos del país y se aplican terapias de distintos orígenes y lógicas curativas en función del paciente y la afección. También los espíritus adquieren formas representativas de dichos lugares, sumándose a la diversidad de apariencias humanas y no humanas de su repertorio mítico, con un común denominador: la alteridad ${ }^{15}$. La ins-

\footnotetext{
${ }^{15}$ «Los espíritus de los cerros son como tsachi, algunos con manpe tsanpa [la ropa tradicional masculina], otros como feto [blancos], como patrones, como doctores, buena camisa, como mujer, como padre, como monjita, como gringa, como otavaleño, como moreno, yukan [mal espíritu], como kayapa [buen espíritu]...» (A. Calazacón, Cóngoma, 1996). Asimismo, en sus invocaciones curativas, el chamán chachi acude a los espíritus de los cerros -del Oriente y de los Andes-, que le ayudarán en sus variadas formas: indios bravos, policías, diablos... (ver Praet 2014: 93-100).
} 
titución chamánica tsachila se reproduce gracias a redes de intercambio establecidas con grupos indígenas vecinos como los cayapas, que a su vez las reproducen con sus vecinos embera (Carrasco 1988: 202; Barrett 1994 [1925]: 293-294) en una red que puede seguir sin solución de continuidad ${ }^{16}$, con muchas regularidades estructurales y formales, no sólo a través de grupos indígenas «afines» selváticos o del litoral, sino también «andinos», «morenos», mestizos y blancos, en sus múltiples manifestaciones de curandería popular (Ventura 2003, 2009, 2011; Praet 2014: 93-100). Esta red se despliega así hacia la Costa, la Sierra y la Amazonía y sabemos que estas regiones participan asimismo de respectivas redes de intercambio (ver Chaumeil 1994, para la Amazonía, y Schweitzer de Palacios y Wörrle 2003, para el conjunto de Ecuador), es decir: con chamanes de otras regiones consideradas ontológicamente tanto similares como distintas según la clasificación de cuatro formas generales de relación y de identificación establecida por Descola (2005), que distingue el animismo, dominante en la selva, del analogismo, en los Andes. Podríamos suponer que el rol que ocupan estos objetos y conocimientos exóticos en la reproducción social y simbólica tsachila y chachi, esta «alteridad constituyente», puede ser igualmente constitutiva de los otros grupos con los que interacciona.

La visión tradicional del mundo tsachila, fuertemente mediada por la institución chamánica, responde a una ontología animista, al igual que la de sus vecinos históricos chachi. Se trata de sociedades que sitúan la humanidad como referencia, no establecen distinciones radicales entre humanos y no humanos, y cuyas mitologías otorgan un lugar central a la transformación entre ambas condiciones ${ }^{17}$. Ahora bien, el mismo Praet ha demostrado que este animismo y algunos de sus aspectos centrales, como la vida y el esfuerzo permanente para fabricar y mantener la humanidad, son compartidos con otros grupos indígenas de distintos continentes; para los chachi, nociones como «forastero» $\mathrm{u}$ «otros pueblos» no tienen sentido: ser humano es una condición restrictiva y abierta a la vez (Praet 2014: 16-21). La incorporación del otro en el chamanismo leída en clave perspectivista -como hace Vilaça (2000) para los wari amazónicos-, i.e. la posibilidad de transformarse en este otro, equivale a la posibilidad real de convertir esta alteridad en uno sin diluirlo, o de devenir otro de forma reversible, sólo posible con seres ontológicamente similares. Los chamanes chachi, con su parafernalia curativa no chachi y su lenguaje exótico, experimentan una metamorfosis en este otro que Praet (2009, 2014: 97-100) define como «monstruo», donde humanidad y monstruosidad son posiciones relativas y reversibles, inconmensurables y equivalentes a la vez: no son categorías dicotómicas o clases sino sólo formas distintas. En la mitología tsachila hay innumerables ejemplos de ello, aunque domina una mayor preocupación por la buena incorporación del otro en uno antes que a la inversa: cuando seres no humanos se aparecen y seducen bajo formas humanas tsachi, y el engaño es descubierto, recobran sus formas previas y desapa-

\footnotetext{
${ }^{16}$ Losonczy (1990: 79) reporta las trayectorias de los chamanes embera del Chocó como parte de su experiencia iniciática en el exterior, entre cuyos destinos se encuentran sibundoyes, guajiros, ingas y tucanos.

17 «Los tigres llegaron bajo la forma de chachi, vestidos con su poncho tradicional...» es el inicio de uno de estos relatos tsachila paradigmáticos, narrado por M. Zaracay, Cóngoma, 1993. No hemos encontrado mitos tsachila en los que otros grupos étnicos ocupen este lugar ontológico que permita la transformación, ni mitos chachi que mencionen explícitamente a los tsachila; pero sí relatos chachi donde la transformación es central: «... las mujeres pecarís aparecían [a un cazador chachi] como mujeres bonitas. A veces lo llevaban a sus casas y hacían el amor. Entonces este chachi parecía cada vez más como un pecarí...» (Praet 2014: 66).
} 
recen o producen desastres ${ }^{18}$ (Ventura 2008). Pero en el chamanismo, el arte de la incorporación se manifiesta por la vía de la negociación con y de la seducción de la alteridad: los entes potencialmente lejanos (menos humanos) se convierten en espíritus auxiliares en una suerte de domesticación que les hará dóciles y solícitos de por vida $^{19}$; al igual que los jornaleros agrícolas de otros orígenes que trabajan para los tsachila, los espíritus auxiliares pueden ser mandados por los chamanes ${ }^{20}$, invirtiendo la relación de protección y sumisión humana a una parte del mundo sobrenatural que podemos encontrar en los Andes, pero sin llegar a constituir ningún submundo cerrado. Por otro lado las enfermedades, como las plantas curativas, participan de la dicotomía frío/caliente común en ontologías analogistas y poco presente en la Amazonía (Descola 2005: 307, 572) sin que por ello sea extensible a otros ámbitos sociales. Cabe señalar que este sistema clasificatorio se encuentra ausente entre los chachi (Barrett 1994 [1925]: 392) y no se ha descrito para los tsachila de principios del siglo XX, por lo que algunos autores (Kvist y Barfod 1994) lo han atribuido a contactos más recientes con los Andes. Esta conjunción de elementos propios de ontologías diversas, contingentes o inherentes, a la vez que ensombrece su adscripción en categorías estancas, refuerza la centralidad de una forma de identificación que trasciende las fronteras sociológicas, eventualmente las ontológicas y definitivamente las etnográficas. Los tsachila, formados históricamente «en el cruce de caminos» (Ventura 2009), aparecen, así, como presumiblemente los chachi, como una metáfora de la modernidad que impregnaba ya en tiempos precolombinos las sociedades amerindias.

\section{A modo de conclusión: repensando las áreas}

A medio camino del salvajismo y la alta civilización; o de un modelo igualitario y otro de jerarquizado; o de una ontología animista y otra analogista; o de una forma de vida costeña o serrana, nuestra área de estudio parece una «anomalía clasificatoria». Cuando el paso del tiempo ya ha dificultado seguir amarrándonos a un conjunto cultural de resonancias precolombinas como es el chibcha o su periferia barbacoa, tenemos abierta una vía para pensar este conjunto no sólo en función de su afinidad lingüística y cultural evidente con los otros parlantes de lenguas sur-barbacoas ${ }^{21}$, sino de las relaciones que ha establecido y establece con otros grupos, de los que obtiene conocimientos necesarios para su reproducción. Lederman (1998) expone cómo la globalización ha contribuido a minar las áreas culturales como marco de referencia para entender las afinidades entre grupos humanos, en pro de la transculturalidad. En este texto, lejos de enfocarnos en la transculturalidad como alternativa a las identificaciones sociales concretas de los grupos humanos, hemos señalado una

\footnotetext{
${ }^{18}$ Una mujer tsachila tiene a la serpiente matacaballo (Sayama pini) por amante. Cuando ella se queda embarazada, el padre y los hermanos van a matar a la serpiente, y la mujer da a luz una niña muy bonita; de mayor, un tsachi la toma como esposa, y en sus amores ella le hace orinar sangre (resumen de un mito tsachila, narrado por A. Aguavil a A. Aguavil, Naranjos, 2005).

${ }^{19}$ «Espíritu del tigre [...] venid con los ponela [chamanes], tomad aguardiente, tomad nepi [ayahuasca], tomad tabaco, venid a darnos fuerza...» (invocación de E. Calazacón, chamán tsachila de Cóngoma, 1993).

${ }^{20}$ «Como trabajadores» explicaba I. Calazacón, chamán tsachila de Cóngoma en 1995.

${ }^{21}$ Salvando las particularidades individuales, en general los tsachila dicen sentirse a gusto con los chachi, grupo con el que han establecido relaciones matrimoniales desde hace al menos un siglo, y a su vez éstos aseguran preferir migrar a territorio tsachila por su afinidad, a pesar de que las lenguas les sean mutuamente incomprensibles.
} 
forma de relación y reproducción antigua, compartida por unos grupos humanos desde tiempos precolombinos. Esta apertura a la alteridad no los hace menos tsachila o menos chachi, o más o menos yumbos, puesto que sus miembros no se definen según grados de civilización o continuidades con el pasado: son la coparticipación en mundos afines, las formas de organización, de relación con el medio y de sociabilidad, muchas veces mediadas por sus lenguas, entre otros rasgos, las que marcarán su identificación. Así, el caso sur-barbacoa, con su ambivalencia histórica, nos ha mostrado su potencial heurístico para repensar las áreas, difuminando fronteras estancas e introduciendo perspectivas más dinámicas y relacionales en la comprensión de las afinidades de los pueblos indígenas. Probablemente sea en esta vía que debamos enfocar el futuro etnográfico de esta región. Ahora nos preocupa cómo las sociedades se piensan en relación a sí mismas y a su entorno; $\mathrm{y}$, como razón de ser de la antropología, nos preocupa quiénes son y qué lugar ocupan los seres humanos desde el punto de vista de un grupo particular, de un conjunto de grupos o de una red.

\section{Referencias}

Adelaar, Willem F. M. 2004. The Languages of the Andes. Nueva York: Cambridge University Press.

Alcina Franch, José. 1990. «La Arqueología de Esmeraldas (Ecuador) a partir de los trabajos de la Misión española», en Culturas indígenas de los Andes Septentrionales, pp. 11-40. Madrid: Quinto Centenario.

Barrett, Samuel Alfred. 1994 (1925). Los indios cayapas del Ecuador. Quito: Abya-Yala.

Barth, Fredrik. 1976 (1969). «Introducción», en Los grupos étnicos y sus fronteras, Fredrik Barth, ed., pp. 9-49. México: Fondo de Cultura Económica.

Beuchat, Henry y Paul Rivet. 1910. Affinités des langues du sud de la Colombie et du Nord de l'Équateur. Groupes Paniquita, Coconuco et Barbacoa. Louvain: J.-B. Istas, Éditeur.

Bouchard, Jean-François. 1998. «Tumaco-La Tolita: un litoral de intercambio en el período prehispánico», en El Área Septentrional Andina. Arqueología y etnohistoria, Mercedes Guinea, ed., pp. 29-41. Quito: Abya-Yala.

- 2010. «Japoto: sitio manteño residencial de la costa central de Manabí». Bulletin de l'Institut Français d'Études Andines 39 (3): 479-501.

Carneiro da Cunha, Manuela y Eduardo Viveiros de Castro, eds. 1993. Amazônia. Etnologia e história indígena. São Paulo: Fundação de Amparo à Pesquisa do Estado de São Paulo.

Carrasco, Eulalia. 1988 (1983). El pueblo chachi. El jeengume avanza. Quito: Abya-Yala.

Cavalcanti-Schiel, Ricardo. 2014. «Cómo construir y sobrepasar fronteras etnográficas. Entre Andes y Amazonía, por ejemplo». Chungará 46 (3): 453-465.

Chaumeil, Jean-Pierre. 1994. «Las redes chamánicas contemporáneas y las relaciones interétnicas en el Alto Amazonas». Revista de Antropología 1 (1): 45-61. Lima.

Constenla Umaña, Adolfo. 1991. Las lenguas del Área Intermedia. Una introducción a su estudio areal. San José: Universidad de Costa Rica.

- 2008. «Estado actual de la subclasificación de las lenguas chibchenses y de la reconstrucción fonológica y gramatical del protochibchense». Lingüistica Chibcha 27: 117-135.

Curnow, Timothy Jowan y Anthony J. Liddicoat. 1998. «The Barbacoan Languages of Colombia and Ecuador». Anthropological Linguistics 40 (3): 384-408.

Descola, Philippe. 2005. Par-delà nature et culture. Paris: Gallimard. 
Descola, Philippe y Anne Christine Taylor. 1993. «Introduction», en «La remontée de l'Amazone: anthropologie et histoire des sociétés amazoniennes». L'Homme 33 (126128): 13-24.

Dickinson, Connie. 2000. «Mirativity in Tsafiki». Studies in Language 24 (2): 379-421.

- 2002. Complex Predicates in Tsafiki. Tesis doctoral. University of Oregon.

. 2011. «Reciprocal Constructions in Tsafiki», en Reciprocal and Semantic Typology, Nicholas Evans et al. eds., pp. 277-314. Amsterdam: John Benjamins Publishing Company.

Faulhaber, Priscila. 2012. "The Production of the Handbook of South American Indians Vol.3 (1936-1948)». Vibrant: Virtual Brazilian Anthropology 9 (1): 82-111.

Fox, Richard G. 2002. «The Study of Historical Transformation in American Anthropology», en Anthropology, by Comparison, Andre Gingrich y Richard G. Fox, eds., pp.167-184. Londres: Routledge.

Galvão, Eduardo. 1979. «Areas culturais indígenas do Brasil: 1900-1959», en Encontro de sociedades: índios e brancos no Brasil, pp. 193-228. Rio de Janeiro: Paz e Terra.

Gómez Rendón, Jorge. 2010. «Deslindes lingüísticos en las tierras bajas del Pacífico ecuatoriano. Primera parte». Antropología. Cuadernos de Investigación 10: 77-107.

González Echevarría, Aurora. 1990. Etnografía y comparación. Bellaterra: Universitat Autònoma de Barcelona.

Greenberg, Joseph H. 1987. Language in the Americas. Stanford: Stanford University Press. Guillaume-Gentil, Nicolas. 1999. «Estudio de un sitio con tolas (montículos artificiales) y con modelo regular: aproximación cronológica de su construcción mediante las tefras». Bulletin de la Société Suisse des Américanistes 63: 25-54.

—. 2010. «Proyecto La Cadena-Quevedo-La Maná. Primera síntesis modal y cronológica así como breves referencias a la Cerámica del Formativo Temprano Final». Bulletin de l'Institut Français d'Études Andines 39 (3): 641-665.

Guinea Bueno, Mercedes. 1981. Patrones de asentamiento en Esmeraldas. Tesis doctoral. Universidad Complutense de Madrid.

-1995. «Presentación», en Cultura y medio ambiente en el área andina septentrional. Mercedes Guinea, Jean-François Bouchard y Jorge Marcos, eds., pp. 3-5. Quito: AbyaYala.

- 1998. «La metalurgia del cobre en la costa norte del Ecuador durante el período de integración», en El Área Septentrional Andina. Arqueología y etnohistoria, Mercedes Guinea, ed., pp.83-110. Quito: Abya-Yala.

- 2010. «Un edificio enterrado ritualmente: la Estructura 1 del montículo J8 del sitio manteño de Japoto, Manabé, Ecuador». Bulletin de l'Institut Français d'Études Andines 39 (3): 503-530.

Hill, Jonathan D., ed. 1996. History, Power and Identity. Ethnogenesis in the Americas, 1492-1992. Iowa City: University of Iowa Press.

Hill, Jonathan D. y Fernando Santos-Granero, eds. 2002. Comparative Arawakan Histories. Rethinking Language Family and Culture Area in Amazonia. Urbana y Chicago: University of Illinois Press.

Jara Chávez, Hólguer. 2007. Tulipe y la cultura Yumbo. Arqueología comprensiva del subtrópico quiteño. Resumen del Vol.11 de la Biblioteca Básica de Quito. Quito: Fondo de Salvamento de Patrimonio Cultural.

Jijón y Caamaño, Jacinto. 1941. El Ecuador Interandino y Occidental antes de la conquista castellana. Tomo II. Quito: Editorial Ecuatoriana. 
Juncosa, José E., ed. 1988. Tsachila. Los clásicos de la etnografia sobre los Colorados (1905-1950). Quito: Abya-Yala.

Kaufman, Terrence. 1990. «Language History in South America: What We Know», en Amazonian Linguistics. Studies in Lowland South American Languages, Doris L. Payne, ed., pp.13-73. Austin: University of Texas Press.

Kvist, Lars Peter y Anders S. Barfod. 1994. «The Curing Rituals of the Cayapa Amerindians of Coastal Ecuador, and their Exchange of Rituals and Medicinal Plants with other Ethnic Groups in the Region», en Las plantas y el hombre, Montserrat Ríos y Henrik Borgtoft Pedersen, eds., pp.149-164. Quito: Abya-Yala.

Lederman, Rena. 1998. «Globalization and the Future of Culture Areas: Melanesianist Anthropology in Transition». Annual Review of Anthropology 27: 427-449.

Lévi-Strauss, Claude. 1991. Histoire de Lynx. Paris: Plon.

Lippi, Ronald D. 1983. «El redescubrimiento de los pueblos Yumbos», en Nueva historia del Ecuador, Vol. 2, pp. 73-74. Quito: Corporación Editora Nacional - Ed. Grijalbo.

- 1986. «La Arqueología de los Yumbos», en Arqueología y etnohistoria del sur de Colombia y norte del Ecuador, José Alcina Franch y Segundo Moreno Yánez eds., pp.189-207. Quito: Banco Central de Ecuador - Abya-Yala.

- 2004. «La expansión de las poblaciones barbacoas en el noroeste del Ecuador». Revista de Arqueología del Área Intermedia 6: 249-276.

Lippi, Ronald D. y Alejandra M. Gudiño. 2013. «Proyecto arqueológico Palmitopamba: Informe Sobre la Temporada de Campo 2012». Quito: Instituto Nacional de Patrimonio Cultural. Manuscrito inédito.

Losonczy, Anne-Marie. 1990. «La Maîtrise du multiple. Corps et espace dans le chamanisme embera du Choco (Colombie)». L'Homme 114: 75-100.

Loukotka, Čestmír. 1935. Clasificación de las lenguas sudamericanas. Lingüística Sudamericana 1. Praga: Tipografía Josef Bartl.

- 1968. Classification of South American Indian Languages. Los Angeles: Latin American Center, University of California.

Marcos, Jorge G. 1981. «Arqueología: Informe sobre el Área Ceremonial del Complejo Manteño-Huancavilca de la Loma de los Cangrejitos, Valle de Chanduy, Ecuador (OGSECh-4)». El Arquitecto 1 (5): 54-63.

- 2012. Visión del Estado Manteño. Disertación presentada por el Dr. Jorge G. Marcos en su incorporación como Miembro Numerario de la Academia Nacional de Historia del Ecuador, 26 de abril de 2012. Manuscrito.

Medina, Henry. 1997. «Los Chachis de Esmeraldas», en Etnografias mínimas del Ecuador, Montserrat Ventura et al., eds., pp. 33-88. Quito: Abya-Yala.

Melatti, Julio Cezar. 1997. Indios da América do Sul. Áreas etnográficas. Brasilia: Instituto de Ciências Sociais, Depto. de Antropologia, Universidade de Brasília.

— 2007 (1970). Índios do Brasil. São Paulo: Editora da Universidade de São Paulo.

Métraux, Alfred. 1950. Les Peaux-Rouges de l'Amérique du Sud. Paris: Bourrelier.

Moore, Bruce R. 1962. «Correspondances in South Barbacoan Chibcha», en Studies in Ecuadorian Indian Languages I, pp. 270-292. Linguistic Series 7, Summer Institute of Linguistics. Norman: University of Oklahoma.

- 1966. «Breves anotaciones acerca de la gramática del idioma Colorado», en Diccionario castellano-colorado/ Colorado-castellano, pp. 96-104. Quito: Instituto Lingüístico de Verano.

Murdock, George Peter. 1951. «South American Culture Areas». Southwestern Journal of Anthropology 7 (4): 415-436. 
Murra, John V. 1948. «The Pacific Coast Tribes», en Handbook of South American Indians. Vol. 4: The Circum Caribean Tribes, Julian H. Steward, ed., pp. 276-291. Washington: Smithsonian Institution.

Palop Martínez, Josefina y Alejandro Cerdá Esteve. 1995. «Asentamientos de indios en el área tropical», en Cultura y medio ambiente en el área andina septentrional, Mercedes Guinea, Jean-François Bouchard y Jorge Marcos, coords., pp. 9-66. Quito: Abya-Yala.

Praet, Istvan. 2009. «Shamanism and Ritual in South America. An Inquiry into Amerindian Shape-Shifting». Journal of the Royal Anthropological Institute 15: 737-754.

- 2014. Animism and the Question of Life. Londres: Routledge.

Renard-Casevitz, France Marie, Thierry Saignes y Anne Christine Taylor. 1988. Al este de los Andes. Relaciones entre las sociedades amazónicas y andinas entre los siglos XV y XVII. Quito: Abya-Yala.

Salomon, Frank. 1980. Los señores étnicos de Quito en la época de los Incas. Otavalo: Instituto Otavaleño de Antropología.

-1983. «Shamanism and Politics in Late Colonial Ecuador». American Ethnologist 10 (3): 413-428.

- 1986. «Yumbo-Ñan: la vialidad indígena en el noroccidente de Pichincha y el trasfondo aborigen del camino de Pedro Vicente Maldonado». Cultura. Revista del Banco Central del Ecuador 24b: 611-626.

- 1997. Yumbos, niguas y tsachila o «colorados» durante la Colonia española. Etnohistoria del noroccidente de Pichincha. Quito: Abya-Yala.

Schweitzerd de Palacios, Dagmar y Bernhard Wörrle, eds. 2003. Heiler zwischen den Welten. Transkulturelle Austauschprozesse im Schamanismus Ecuadors. Marburgo: Curupira

Stark, Louisa R. 1983. «Las lenguas indígenas de las tierras bajas de Ecuador: historia y condiciones actuales». América Indígena 43 (4): 797-820.

Steward, Julian H., ed. 1948. Handbook of South American Indians. Vol. 4: The Circum Caribbean Tribes. Washington: Smithsonian Institution.

- 1949. «South American Cultures: An Interpretative Summary», en Handbook of South American Indians. Vol. 5: The Comparative Ethnology of South American Indians, Julian H. Steward ed., pp. 669-772. Washington: Smithsonian Institution.

Swadesh, Mauricio. 1959. Mapas de clasificación lingüística de México y las Américas. México: Universidad Nacional Autónoma de México.

Taylor, Anne Christine. 1984. «L'américanisme tropical, une frontière fossile de l'ethnologie?», en Histoires de l'anthropologie (XVI-XIXe siècles), Britta Rupp-Eisenreich, ed., pp. 213-232. Paris: Klincksieck.

Tovar, Antonio y Consuelo Larrucea de Tovar. 1984. Catálogo de las lenguas de América del Sur (Nueva edición refundida). Madrid: Gredos.

Ugalde, María Fernanda. 2006. «Difusión en el período de Desarrollo Regional: algunos aspectos de la iconografía Tumaco-Tolita». Bulletin de l'Institut Français d'Études Andines 35 (3): 397-407.

Ventura i Oller, Montserrat. 2000. «Several Representations, Internal Diversity, One Singular People». Social Anthropology 8 (1): 61-67.

- 2003. «Schamanische Austauschbeziehungen und Identität. Das Netzwerk der Colorados», en Heiler zwischen den Welten. Transkulturelle Austauschprozesse im Schamanismus Ecuadors, Dagmar Schweitzer de Palacios y Bernhard Wörrle, eds., pp.7395. Marburgo: Curupira. 
—. 2008. «Relaciones interespecies en las tierras bajas de América del Sur», en Identidades ambivalentes en América latina (siglos XVI-XXI) Verena Stolcke y Alexandre Coello, eds., pp.113-129. Barcelona: Bellaterra Ediciones.

- 2009. Identité, cosmologie et chamanisme des Tsachila de l'Équateur. À la croisée des chemins. Paris: L'Harmattan. (Versión en español: En el cruce de caminos. Identidad, cosmología y chamanismo tsachila. Quito: FLACSO, Abya-Yala, IFEA, 2012).

—.2011. «Redes chamánicas desde el punto de vista tsachila». Nuevo Mundo Mundos Nuevos. https://doi.org/10.4000/nuevomundo.61200.

- 2012. «Chamanismo, liderazgo y poder indígena: el caso tsachila». Revista Española de Antropología Americana 42 (1): 91-106.

Vignaud, Henry. 1919. «L'Américanisme et la Société des Américanistes». Journal de la Société des Américanistes 11: 1-20.

Vilaça, Aparecida. 2000. «O que significa tornar-se outro? Xamanismo e contato interétnico na Amazônia». Revista Brasileira de Ciências Sociais 15 (44): 56-72.

Whitehead, Neil L., ed. 2003. Histories and Historicities in Amazonia. Lincoln: University of Nebraska Press.

Wilbert, Johannes. 1968. «Loukotka's Classification of South American Indian Languages», en Classification of South American Indian Languages, Čestmír Loukotka, ed., pp. 7-23. Los Angeles: Latin American Centre, University of California.

Wolf, Eric. 1982. Europe and the People without History. Berkeley: University of California Press. 